\title{
Traditional Arts and Socio-Cultural Changes: The Case of Bags in the Bamenda Grassfields of Cameroon
}

\author{
Exodus TIKERE MOFFOR
}

\author{
The University of Yaoundé 1, Cameroon
}

\begin{abstract}
The bag like any other aspect of art is an important cultural heritage of every society. As Frank Boas puts it arts and man are inseparable, and that no society can exist without arts. In the Bamenda Grassfields, bag production is done by a few cultures and such activity performed absolutely by the men has been handed down from one generation to another with very little modification. In the pre-colonial days, traditional bags were produced with three major raw materials namely animal skin, fibre and a special fabric called ndop. But today, with the challenges of modernity, the traditional bags of the Bamenda Grassfieds is undergoing gradual modifications both in materials used in production and function. Despite these changes noticed in the manufacture as well as use of the traditional bag, this receptacle still fulfils its functions some of which are to store and carry objects. They are also used to provide healing to patients. Bags can also be used to portray the socio-political organisation of the Bamenda Grassfielders. They are elements of social stratification and cultural identity; they therefore have roles in politics, social, religion, economics and healing.

Data for this research was carried using the qualitative as well as the quantitative methods and the information was analysed soon after the data collection was over.
\end{abstract}

Keywords: Tradition, arts, change, bag, cultural heritage, socio-culture

\section{Introduction}

A bag is a receptacle, a flexible container made of cloth, paper, plastic and fibre. The bag is a very useful instrument in every community. The traditional bags which are discussed in the research paper are those made of raffia fibre, animal skin and the $n d o p$ fabric. According to Venice and Alastair Lamb (1981: 139),

Raffia weaving occurs all over Africa where the raffia palm is found. It is important in Madagascar. In Angola, Zaire, Congo and Gabon, it is by far the most significant form of indigenous textile production. In Cameroon, the use of raffia is more or less confined in the Grasslands where Bamessing or the Ndop Plain and the Meta region around Mbengwi are the major centres.

Bags can be used for storage, packaging of food and other items. The bag can also be used to store traditional medicine. There are bags of different sizes, shapes and colours. In the Grassfields of Cameroon, bags go beyond mere carrying of food and storage of medicine; it is used as an element to spot evil persons in the society and also an element of social stratification. Some bags are embroidered with emblematic motifs and such bags are used only by the royalty and the ruling class. In the Bamenda Grassfields, bags are fabricated with a variety of materials ranging from fibre, animal skin to fabric. Bags are hardly produced from nylon materials. In this area, bags are produced predominantly in the Meta area in Momo Division and in Bamessing in Ngoketunjia Division. Bags production is an activity which is predominantly male. Women can only assist in the collection of fibre which is the most used raw material for bags fabrication. Bags accomplish different functions some of which are political, religious, social and healing.

In the Bamenda Grassfields of Cameroon, the traditional bag is very visible in cultural ceremonies, men, women, commoners and notables carry bags which match their social ranks. The Bamenda Grassfields is a region that corresponds to the Anglophone North West Region of the Republic of Cameroon. The part of Grassfields that was under English Administration known as the 'Bamenda Grassfields'1 (Warnier, 1975: 43).

The natural vegetation of this region consists of short and tall grasses with raffia and oil palms growing along the courses of the rivers and streams and banana trees surrounding the compounds. The oil and raffia palms serve as raw materials to weavers who use them for the production of baskets, bags, caps, mats, chairs, tables, cupboards and thatches.

All the peoples of the Grassfields are organised in fondoms of different sizes. Most of them are independent (Warnier, 1975: 42). Almost everywhere, chiefdomship is hereditary and the fonis a sacred figure. The distribution of power between fons, regulatory societies, lineage and ward heads varied from chiefdom to chiefdom as well as the degree of concentration of power, the less centralised being probably the Meta is among stateless societies (Warnier, 1975: 32-3). The political structure of most, if not all,

\footnotetext{
1 'Bamenda Grassfields' after World War 1, Cameroon a former German colony was divided into two: one part (the greater part) was put under French administration under the League of Nations Mandate, while the Western remaining part was mandated to the British who administered it as part of Nigeria. The part of the Grassfields that was under English rule was called 'Bamenda Grassfield.'
} 
Bamenda Grassfields fondoms are, basically similar. The fon has very great executive authority next to the village regulatory society known as kwifon. Chiefs, notables and quarter heads also form part of the political structure. Most Bamenda Grassfields fondoms are patrilineal (apart from the Kom and the Aghem societies are matrilineal) and highly ranked societies. The political system is based on hereditary traditional authority and access to power is highly determined by direct descent. On the political strata of these chiefdoms therefore, the kwifon comes first followed by the fon, notables and quarter-heads. And only the fon and a few notables have the privilege to used specially decorated woven bags.

\section{Methodology}

This piece of work is an attempt to demonstrate the dynamics of the traditional bags and the need for its revival. To collect data for this paper, the qualitative and quantitative methods were used. Underlying these moethods, the following research technoiques were emplyed: direct observation, indepth-interview and questionnaire. The writers of this paper visited many fondoms of the Bamenda Grassfields where he saw the fabrication of different traditional bags. He also took part in the production of bags by collecting fibre.He also visited many cultural ceremonies where these bagsare being used. He interviewed the notables on several occasions to know when they use these bags, and who uses what type of bag. With the women, he was out to find out the type of bag used in storing their cups and other items. He also interviewed young people and traditional medical doctors to understand in what ways they use the traditional bags. Questionnaires were equally used and among some of the information that were provided by the questionnaire was the livelihood of the people especially the king makers and other notables, bags production, acquisition of bags, marketing of the object, and societal perception of the bagsin the Bamenda Grassfields societies.

\section{Data management analysis}

Data analysis of the study began soon after our field work. Information recorded during observation and interview sessions were transcribed and arranged according to the different categories of people interviewed.

\section{Findings}

Findings disclose that bags are an aspect of art which cuts across all the facets of the culture. Their production is reserved absolutely for the men folks; Venice and Alastair Lamb (1981: 139) note that in Cameroon as elsewhere in Africa, raffia weaving is a male craft. All stages from the preparation of the raffia fibre through the weaving to the sewing up of the finished articles, bags and costumes, is carried out by men, most of whom belong to families which have been engaged in this occupation for many generations. But today, the women are engaged in the collection of raffia fibre which is used by the men for production. The functions of these bags rang from political, religious, social, healing to economic are produced from materials got from the immediate environment

\section{Political functions of Bags}

In the majority of Grassfields chiefdoms, some bags are used only by the ruling class (the fon, chiefs and notables).This is to distinguish them and their functions from the commoners. They use bags during special ceremonies such as death celebrations, funerals and twins' celebrations. The fon for example uses special bags with specific motifs like the bag below which bears the lizard symbol. This bag is used to store traditional elements that he needs for the service of the chiefdom.

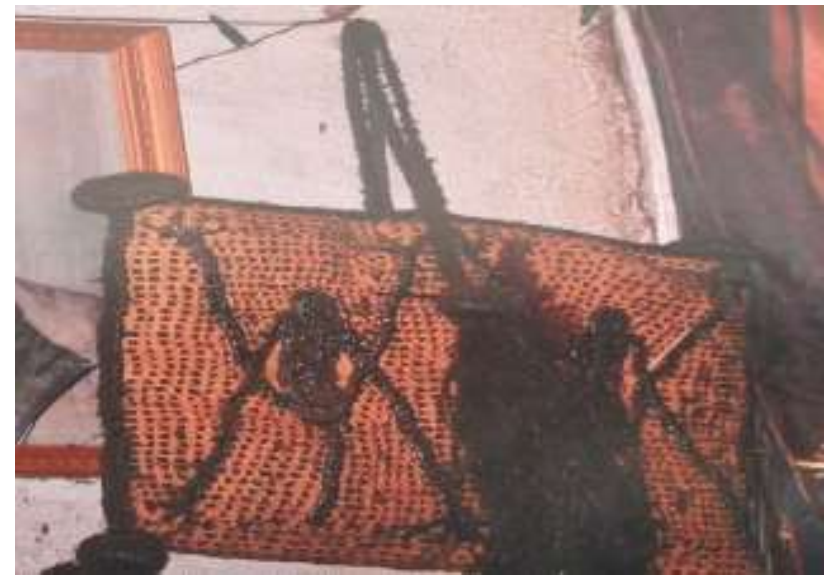

Plate 1: A bag adorned with the lizard motif. Photo Tikere (16/10/2017)

On an officer outing to a death celebration or a funeral ceremony, the fon's bag which contains camwood and other items are carried by one of his chinda's. The camwood in this bag is used to anoint the deceased in the case of a funeral. This product from the camwood tree which has the colour of blood permits the deceased to be ushered in the realm of the living death. It is also a means of wishing him farewell and upon the anointing of the camwood, incantations are being done in words like

Nju (calls the name of the deceased) as you travel to meet our fathers and fore fathers (ancestors) who have gone ahead of you, may you go well, have peace where you are going, explain to them how we are faring. We bite you farewell but that as you go you continue to watch over us (Tah Nambeh, 12/01/2010) 
This is done because the people of the Bamenda Grassfields like majority of Africans believe that there is life after death and those who have gone beyond watch, guide and guard the living.

This is conducted by the fon himself if the deceased is a notable or king maker but in other cases, this is performed by the fon's representative who could be a prince or the chief priest. At the level of the clan, the clan head conducts the rites.

In most Bamenda Grassfileds cultures, the palace has a bag which contains some potent potion used to spot out evil doers. If someone steals for instance and does not want to own up as the culprit, the fon will use this bag which he will ask all the villagers to take turns to touch and the individual whose hand gets stock on it is the criminal. The same bag is used to banish evil doers from the society. Evil doers are people who perform acts that are detrimental both to individuals and the society. Some evil doers are witches, wizards or murderers. When the culprit is escorted at the limits of the village, some of the potion which is in the bag is brought out and blown behind him/her thereby signifying that as he/she is leaving the village, he/she should never return else he/she will die without entering the land. This bag therefore acts as a form of social control, discouraging stealing and other ills in the society.

There are other bags that are reserved only for the royal family and some of these bags have symbolic motifs such as the leopard skin, the traditional wear of the Grassfields commonly called ndop and cowry shells. A bag made of leopard skin is used only by the fon because he is regarded as a leopard.

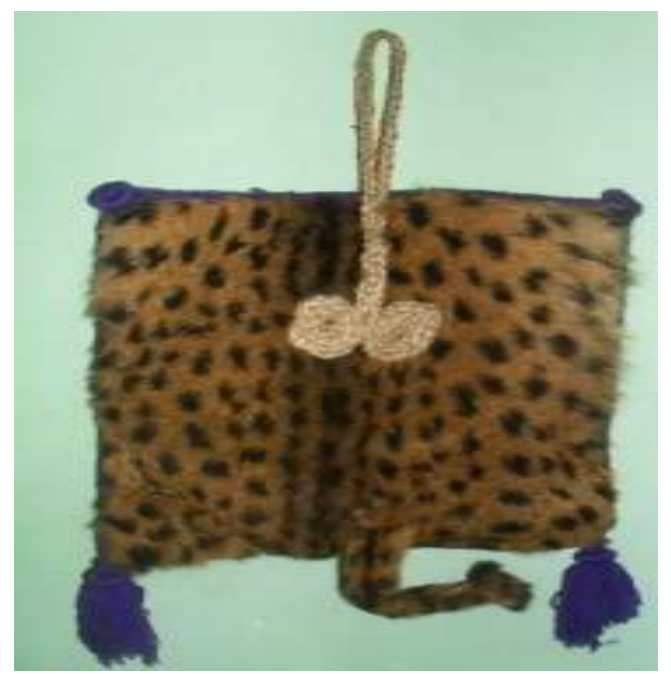

Plate 2: A bag decorated with the leopard skin. Photo Tikere (10/09/2015)

Cowry shells decorated bags are carried by princess during very important cultural ceremonies like the enthronement of a fon, chief and the annual dance. This bag together with the traditional attire is used to identify children from the royal family.

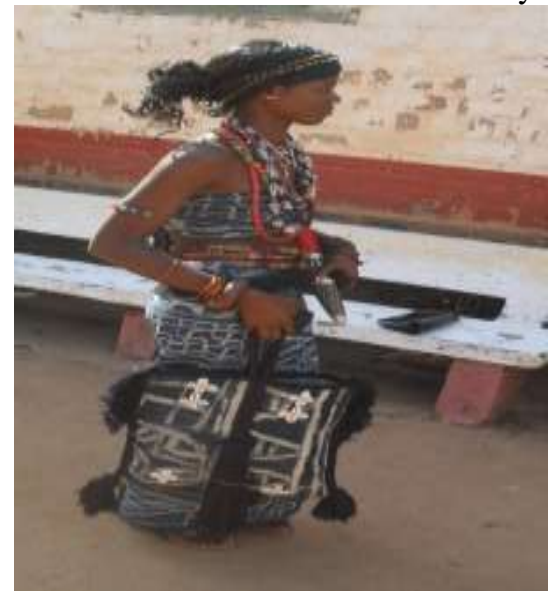

Plate 3: A princess of the Bafut chiefdom carrying a bag made with the ndop fabric decorated with cowry shells. Photo Tikere (17/12/2012)

As we can see in the picture above, the lady is a princess in the Bafut chiefdom, this is recognisable in her traditional dressing of the ndop fabric, necklaces and she carries a horse tail and a titled bag. Her dresses and the objects she carries are symbolic marks of honour, honour which she acquires by birth.

Bags are used as a title objects. In most Bamenda Grassfields chiefdoms, people are usually identified because of the contributions they make in the development of the society. One such identification marks is the award of titles to distinguish those who have contributed to the growth of the society and a form of encouragement of hard work. During the annual dance (abinemfororleleh,)of 
the Bafut chiefdom for example, there is usually the award of traditional titles to distinguish personalities, people who have carried out very important contributions in the chiefdom. These titles among which are traditional bags, cups, the red feather and the pine of the porcupine are handed by the fon of Bafut himself to the beneficiaries. The bags are produced with are of different materials bearing diverse colours. As can be seen in the plates below, there are two of such bags, the first made of red fabric and the next of fibre.

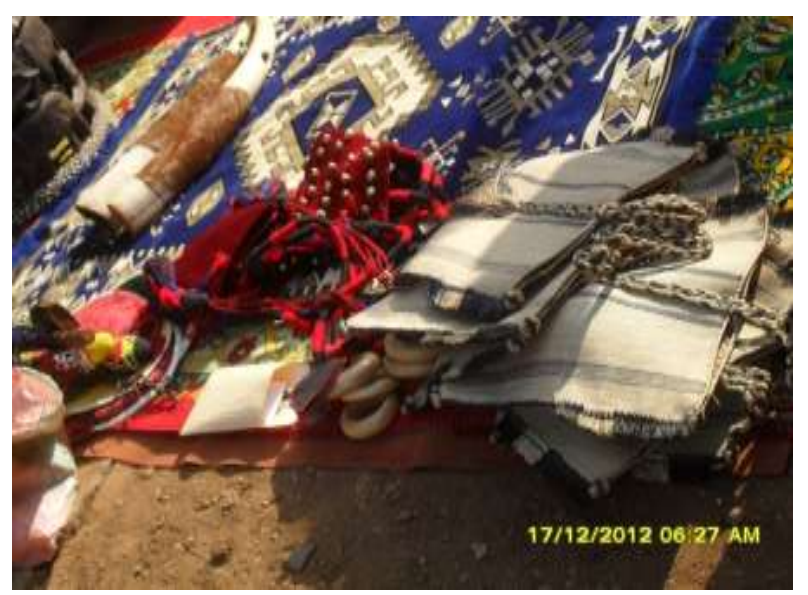

Plate 4: Title bags. Photo Tikere (17/12/2012)

The red bag is given to both male and female. This bag is embroidered, embellished with some golden bells attached on it. It is worn on the neck of the initiate by the fon. This is the first class title which Bafut people called barmegum.

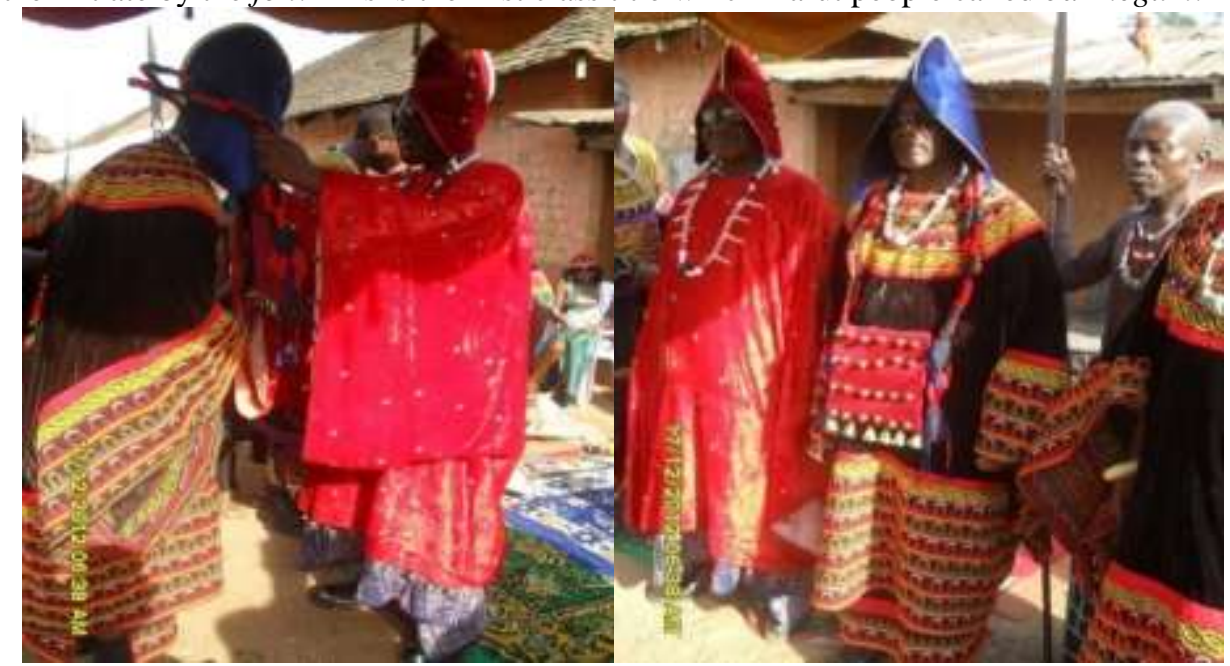

Plates 5 and 6: The fon awarding a title bag to some Bafut elites. Photo Tikere (17/12/2012)

This same title is given to women but the difference is in the size of the bag awarded to women. The bag given to women is smaller than that handed to men. Women are awarded only the bag but some men are also given the royal sword known as anguieh. There are very few women who are honoured with such a title.

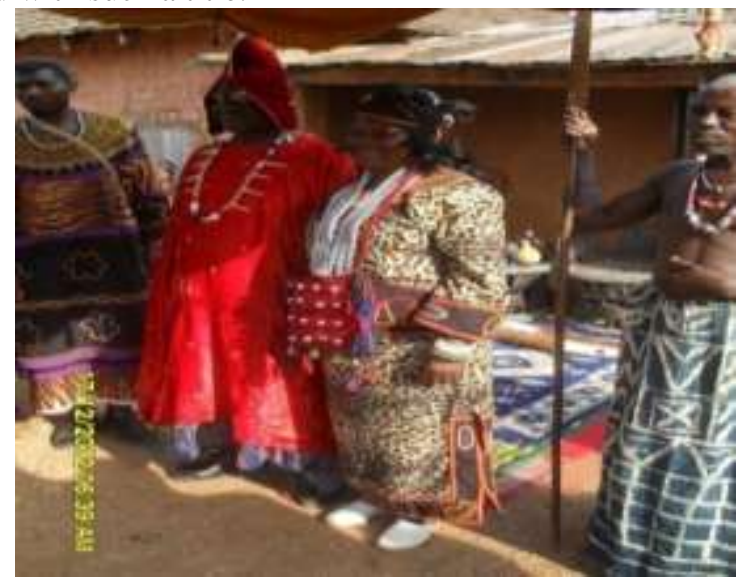

Plate 7: A title bag awarded to a woman. Photo Tikere (17/12/2012)

The red bag is handed to people who have either carried out projects such as a building project, water project and so on. As the fon hands these titles to the recipients, he uses these words 
The people of Bafut (including the ancestors) have seen what you have done and want to encourage you to continue to do more. Building a place does not necessarily mean that you come from there. Developers will strive to have an impact wherever they fine themselves. We say thank you, the gods appreciate you and may you have a long life (fon Abumbi II of Bafut). 25/03/2015).

The next type of bag is made of fibre is awarded to women alongside the title cup, a small round calabash (mo'oh) with a small hole bored on it. This calabash might be used by these title women in the place of the mo'oh tong. The calabash is handed to the initiate who holds it in the left hand and the woven bag is put on the right hand. This title is given to teachers, medical doctors to name these few. The contribution of the above mentioned persons is immense in the culture of Bafut. This is the third class title which is the equivalent of the red feather for the men.

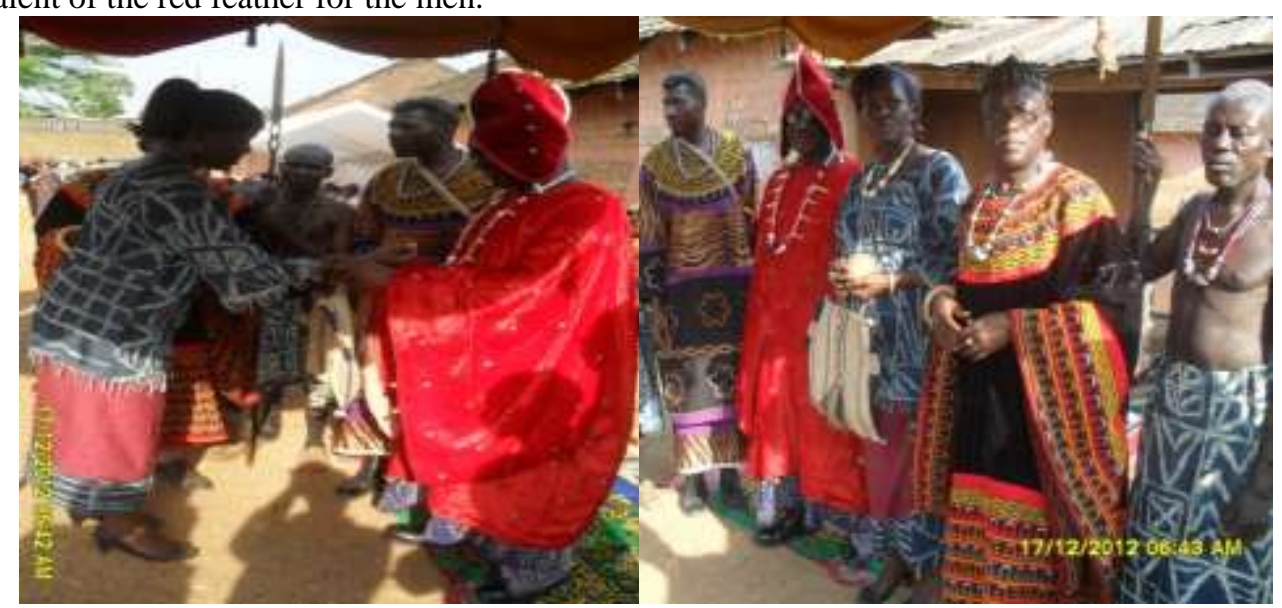

Plates 8 and 9: The award of fibre bags to a distinguished Bafut woman. Photo Tikere (17/12/2012)

The bag here plays a dual role; it serves as a sign of tribute and a container in which the title cup is put. These title symbols (the bag and the cup) are carried to cultural ceremonies and who aver meets someone with this title, gives her the respect which she deserves.

In the Bambui cultural sphere, notables like the one which is in the plate below (Ta Mekezang) keeps his title bags at home. Such bags are hung on the wall with their contains prepared to solve specific problems or each bag has a specific occasion in which the notable has to use. These bags even when its owner is absence, no one can look into or touch it for fear that the potent potion in it can harm or affect him or her.

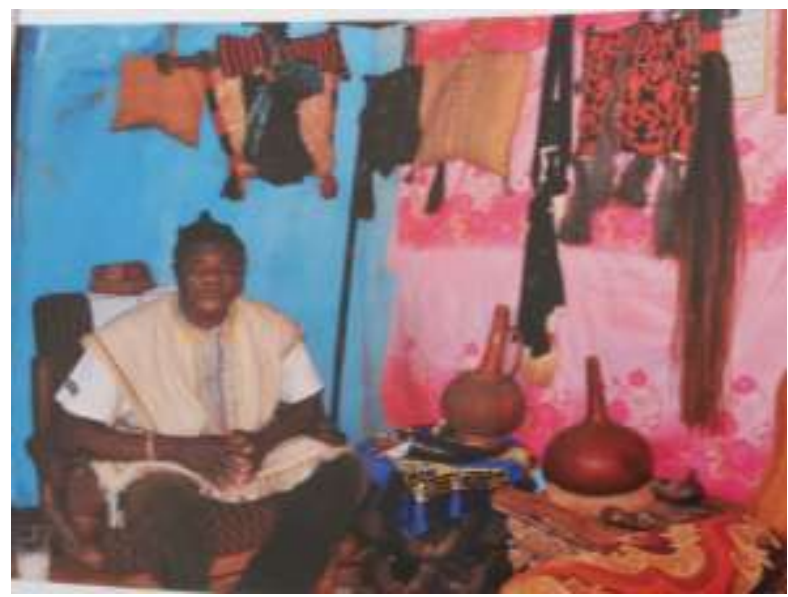

Plate 10: The bags of a notable hanging on the wall. Photo Tikere (10/09/2015)

When a 'big' notable or a 'big' title holder dies, his 'bag' is handed down to his successor. This bag which is transferred from one successor to another, from one generation to the next, serves as the heart bit of the entire family. Such a bag is handled and handed either by the fon or by a king maker because it does not warrant everyone in the society to touch or see into it. This bag is handed only to a male successor. This means that in the cultural sphere of the Bamenda Grassfields, if a man dies without having a male child, his successor can come among his girl children but this female successor will not use the bag, stool, title cup or any other status symbol that she inherits. These objects are handed to her male child who will succeed her father. The female successor is therefore a sort care taker because the position cannot be vacant. It is important to note that only the bags of hereditary notables are transmitted from one generation to another. The powers that the bags of other notables possess die at the death of their owners.

Bags are used as an element of social stratification. Themajority of Bamenda Grassfields chiefdoms are highly stratified, people occupy different social positions and such positions are empowered with some social stratification symbols and the traditional bag 
is one of such. The fon occupies the highest social rank followed by the chiefs, the king makers, notables, and traditional medical doctors. The commoners are at the tail of the social strata.

The fon embodied the society, and to Nkwi and Warnier (1982: 62), he is hyper-social and hyper-cultural. Whereas the encroachment of nature on the cultural universe of the chiefdom is seen as polluting, the influence of the hyper-cultural fon is seen as a blessing and as constantly regenerating the society. The fon is hyper-social and hyper-cultural because he embodies what human society is all about; the alliance between in-laws (the fon had many wives and married off his many daughters), the alliance between clans, lineages and quarters in the societies of the chiefdom, the social rules and norms, and the contact with the ancestors who warranted the social order and the prosperity of the society. This is why the fon, in olden days, was never involved in repression. Repression and social control must deal with polluting actions, and the fon belonged to the opposite pole of human society, the cultural pole, which is free from pollution and danger. He was therefore, kept away from any polluting contact and was never involved in social control and repression except as a moderator. The fon who is at the top, uses bags with the ndop fabric and the lizard motifs among others. Him and the position he occupies are regarded as the biggest in the entire society. The fon is not bigger than all the other persons in his society but the powers vested on him by the ancestors and his people determine his grandeur.

The chiefs, king makers, notables and traditional healers all can use bags embellished with cowry shells. The above mentioned personalities apart from the traditional healers are part of the ruling class and have the distinguish authority and functions which permit them to possess and use objects with an emblematic symbol like the cowries. The tiloh or sub chief comes immediately after the fon on the political strata of Bamenda Grassfields. The tiloh is usually referred to as the hereditary rulers, council of elders or clan heads. Most of them are migrants who came to Kedjom with their own kwifon societies but surrendered them since two kwifons cannot govern the same chiefdom. Being very instrumental in their various chiefdoms, they work hand in hand with the fon in the management of the village. They are the fon's advisers; they appoint and crown a successor when a fon is 'missing' and they are equally the core of the kwifon society.

Becheh or king makers are equally very important notables in the Bamenda Grassfields. These are old princes who are members of kwifon. It is important to note that when a fon is $y a^{\prime}$ 'ah or crowned, princes in his generation cannot be members of the kwifon else all of them will be equal (to the fon). This therefore, means that becheh are princes, three to four generations to that of the fon. They can become members of the kwifon because of their seniority in the palace. Being components of the ruling class, they together with betiloh administer the affairs of the chiefdom, advising the fon on very important issues and also taking part in the 'catching' or appointing and crowning of a new fon.

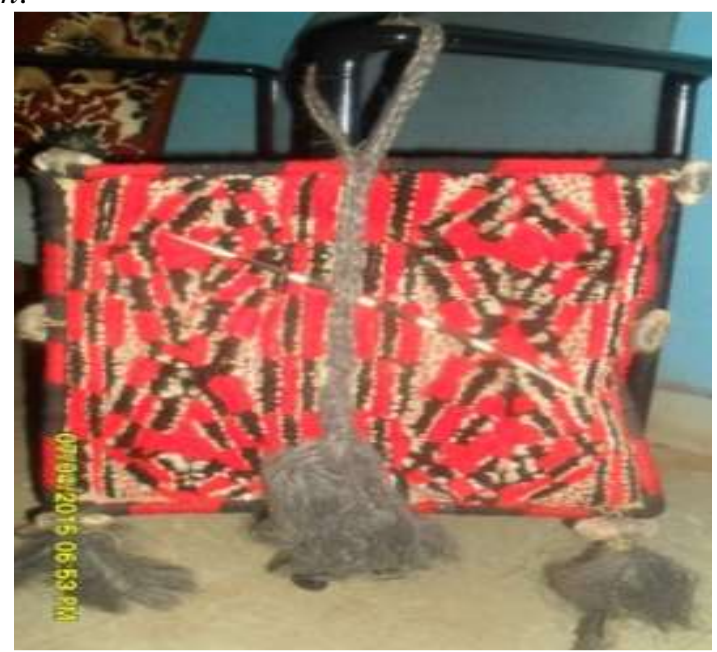

Plate 11: A title bag. Photo Tikere (07/04/2015)

A bag like the one above, reserved for big notables. This bag as can be seen has the pine of the porcupine on it. The object is the highest title among the Bamenda Grassfields, thus anyone who has it either on his cap or bag is either a fon, chief, and king maker. Just as this animal uses the pine to protect itself against predators, these personalities use this title symbol to demonstrate their role one of which is to protect as well as work for the interest of the society?

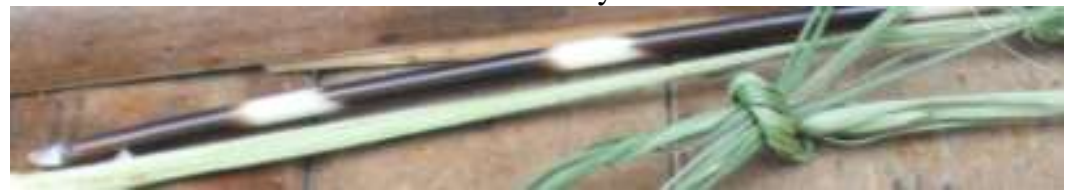

Plate 12: The pine of the porcupine. Photo Tikere (07/04/2015)

Traditional medical doctors on their part have the immense role of providing medical care in the entire society: by healing the sick, sending away evil spirits from people and safeguarding the entire society. Below is the picture of a traditional healer who uses his bags adorned with cowry shells in restoring the health of his patients. 


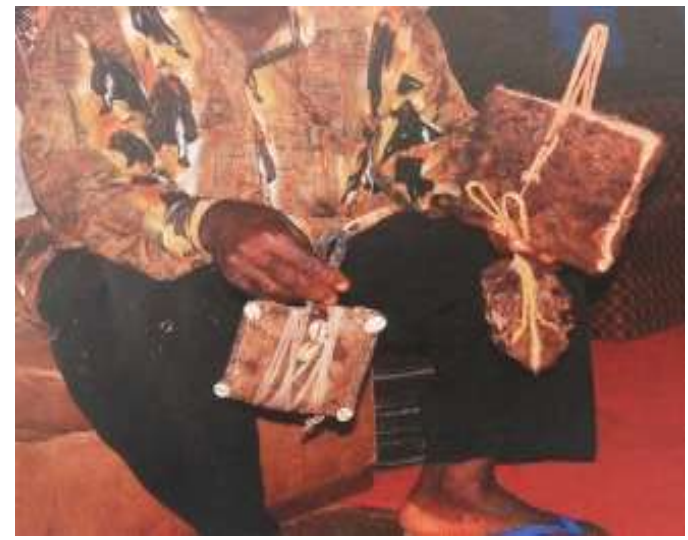

Plate 13: Animal skin bags used to store powdered medicine. Photo Tikere (16/10/2017)

Commoners, who occupy the last position on the social ladder, use 'common' bags, bags which do not have any significant designs wand as a result do not have any cultural consequence in the society. The bags possessed and used by this category have only one function, to store and carry their common cups to cultural celebrations: traditional marriages, death celebrations, funerals and succession ceremonies. If a commoner works hard and impacts the development of his society as discussed above, he or she can climb horizontally to a more honourable position where he or she can have the prerogative to use title objects like the bag.

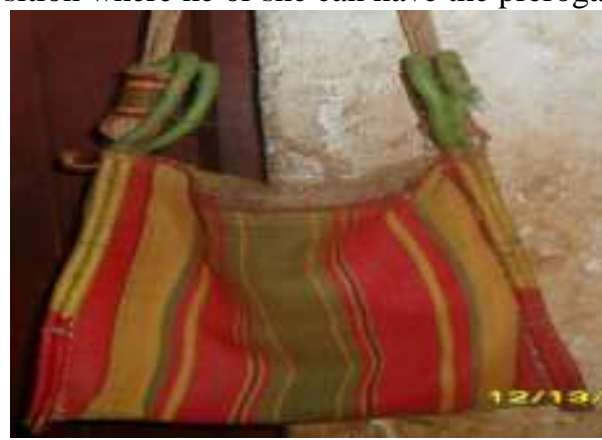

Plate 14: A bag reserved for a commoner. Photo Tikere (13/12/2018)

\section{Religious functions of bags}

Religion plays a very important part in the lives of the Grassfielders in general and the Bamenda Grassfields in particular. The majority of Grassfields people believe that spiritual forces reside in objects such as bags, stones, trees and others. During very important celebrations among these people, the traditional bag is used to store or carry medicine or camwood which is used in the ceremony. In a death celebration for example, masquerades carry bags which contain the powers of this group, this bag in the Bambui language is called boorand then the name of the juju or masquerade is mentioned. Boorkechufor instance is the bag of kechu. Kechu is the name of a masquerade or juju in the Bambui fondom. It is important to note that each dance group or masquerade or juju in the Bamenda Grassfieldshas its 'bag' in which its powers resided. The bag is also referred to as the spirit of the juju. Such a bag is handled and used to wade away other forces which may interrupt in its activities or make it not to perform and function well. Occasions in which masquerades have to perform is an opportunity for them to test the strength of their bags. The strength of a masquerade is measured in the strength of its bag.

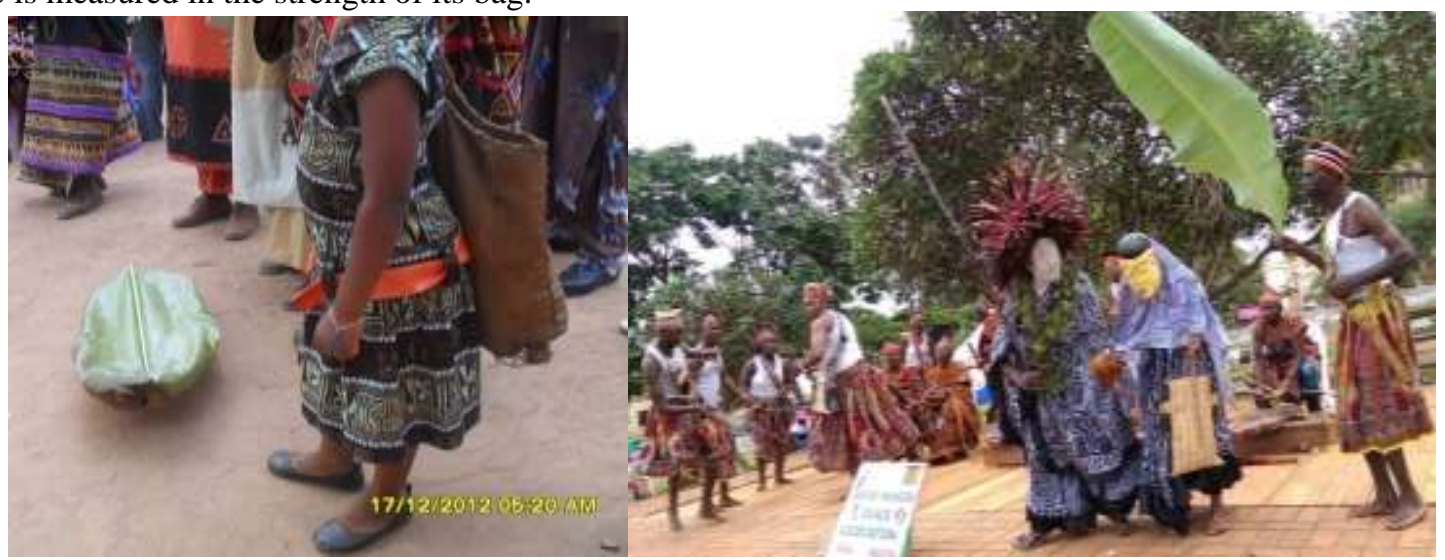

Plates 15 and 16: Bags used in cultural celebrations. Photo Tikere (17/12/2012)

Some of such bags contain the camwood as has been mentioned above. The camwood is a very important element in the cultures of the Bamenda Grassfields people. It is used in many traditional rites such as rites of passage, traditional marriages, enthronement of the fon , burials, initiation rites, twins' celebrations, in succession rites to name only these. The camwood is sometimes applied 
dry and sometimes it is mixed with palm oil. During burial, it is used to rub the corpse before it is lowered into the grave. This is to say fare well to the deceased. In traditional marriages, mixed camwood with palm oil is anointed on the bride and the groom. It is believed that this will render the couple to be very humble if at all they or one of them was cruel or brutal. This is thus a panacea for cruel behaviour.

Among the Kom people, there is a special rite of passage where young women pass to motherhood. In this rite, the woman is accompanied round the compound with other dancers who are all women, who are members of this group. The initiate dances bear body with her body anointed with camwood from her head to her toes. She is decorated with a series of beaded chains and she dances with a long symbolic anthropomorphic walking stick. The woman dancing in front or leading the dance carries a woven bag. This bag usually serves as a container in which the initiate stores her drinking cup and other items which she may need in any cultural event.

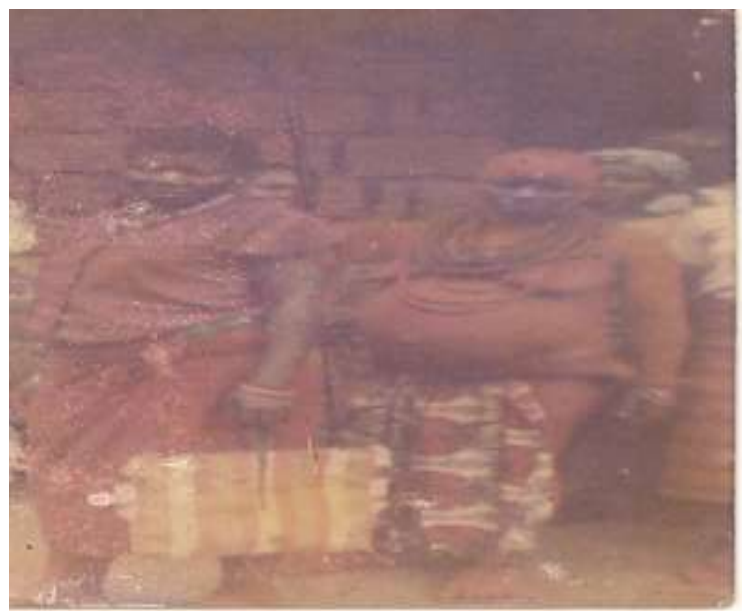

Plate 17: Rite of passage in Kom. Photo Tikere (10/02/1980)

Through this ceremony therefore, particular women move from one category to another. This superior category, permits them to attend certain meetings and enter certain houses in Kom. She has the right to associate with some important women in the Kom society.

This type of bag is handed to a widow among the Bamileke after widowhood rites. She carries the bag to every ceremony that holds in the society.

The traditional bag is also very valuable to priests and pastors of the Catholic and Presbyterian churches. These servants of God use the bags to carry their Bibles and other small objects which they need to serve mass. The very first missionaries and priests and pastors who came to Africa and Cameroon in particular discouraged the natives from using their traditional art among which where bags with the pretext that they do not glorify God. Today, they have started using the bags in for the service of the Lord because they have found out that it is part of the cultural heritage of this people.

\section{Bags and Healing}

In the Bamenda Grassfields like in the majority of African cultures, traditional medicine is part and parcel of the people culture. They go for this because they believe in it and it is as old as the culture itself. Some traditional medicines are stored in bags and bags used by traditional doctors are made of two principal materials: fibre and animal skin. Fibre bags are usually used to store harvested herbs. Harvesting of herbs is usually done very early in the morning when the leaves still have all the medicinal properties in them.
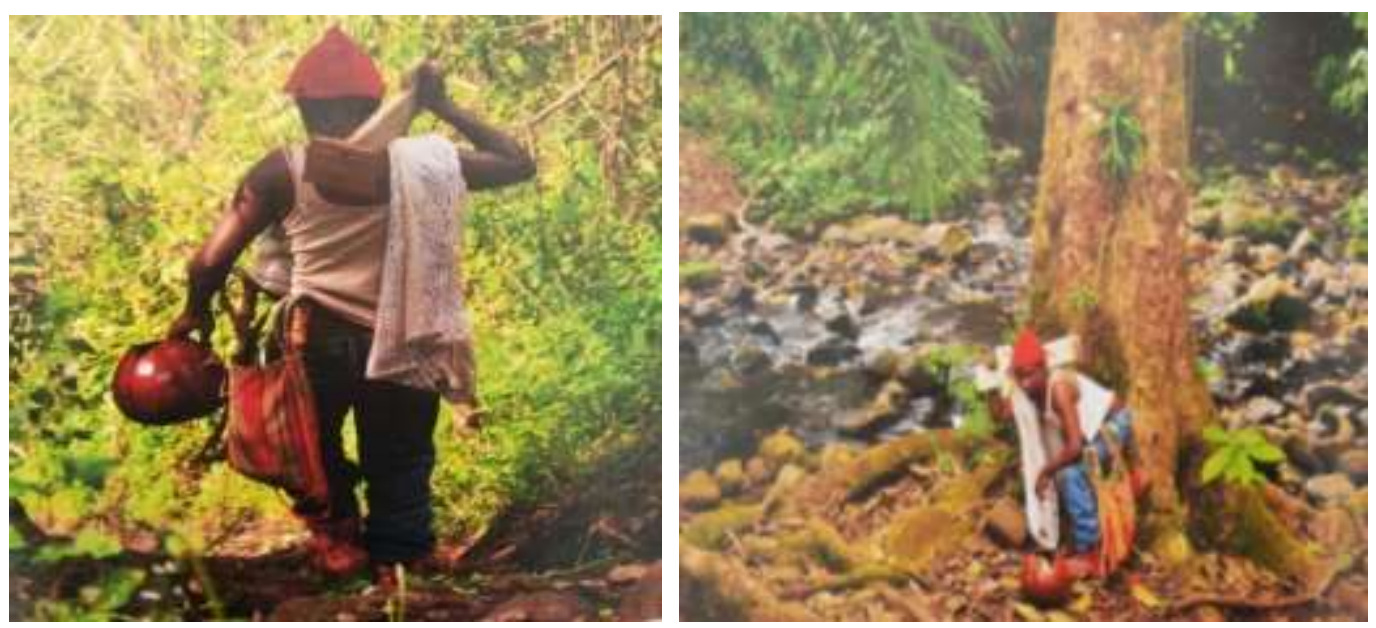


\section{Plates 18 and 19: A traditional doctor going to harvest herbs. Photo Tikere (16/10/2017)}

Traditional doctors store most of their powder medicine in bags made of animal skin. Such medicines are pounded in the mortar meanwhile others are ground on the stone. The colours of the medicines vary from black, white, yellow to brown. Each bag will contain specific medicine destined to cure a particular ailment.

When most patients who suffer from frontal headache and chest ache consult a traditional healer, a bag containing some potion is place on the affected part. The medicine is expected to send out the spirit or heal the portion of the body which is malfunctioned.

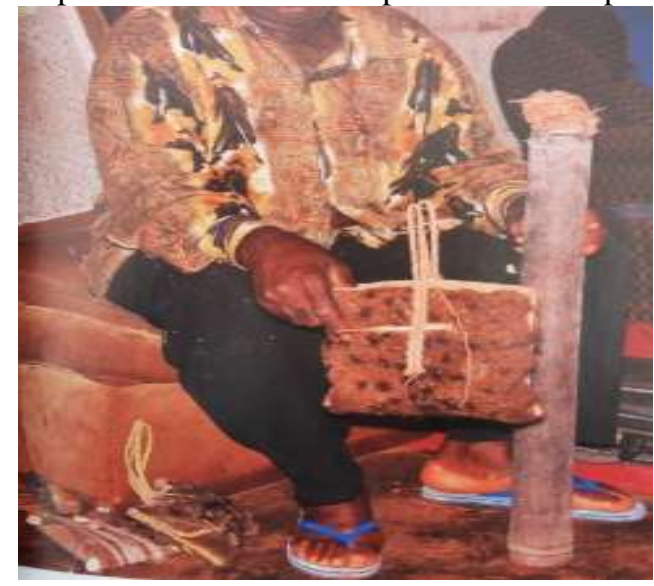

Plate 20: A bag containing potion. Photo Tikere (16/10/2017)

Some of such bags are often seen hanging on the wall in the healer's healing room. Many of them are above five decades old but their contains are renewed every year to maintain their effectiveness. Some of these bags are handed down from father to son upon succession. Children succeed their parents and when they do, they continue with their parents' activities and responsibilities.
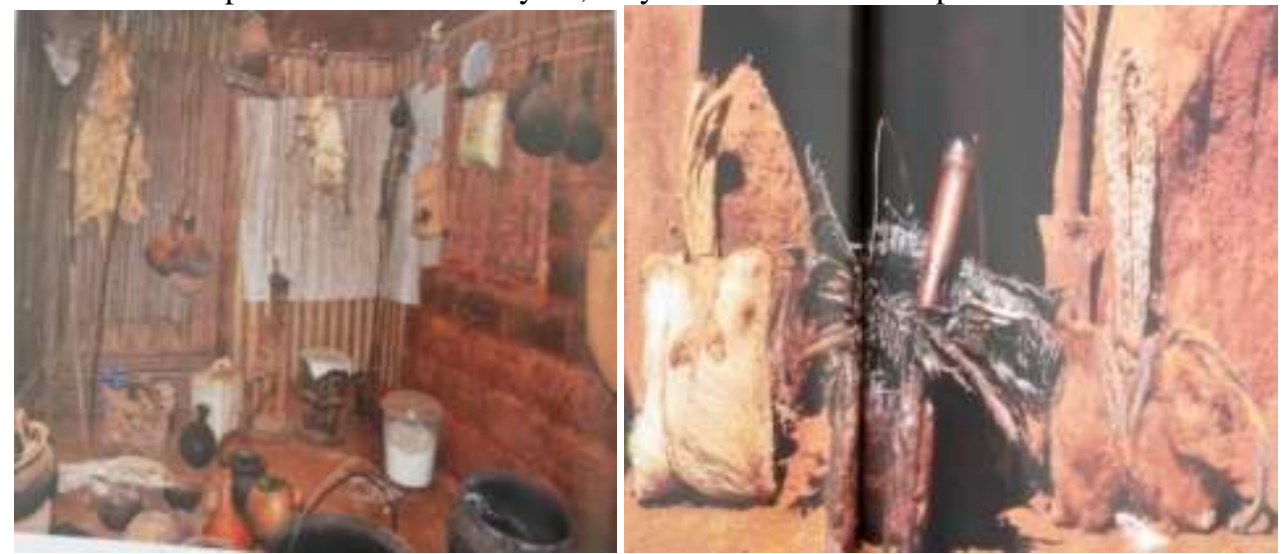

Plates 21 and 22: Pictures showing bags hung on the wall of a healer's room. Photo Tikere (16/10/2017)

Traditional medicine men sometimes produce a small bag that they give to their clients or patients to tie on the waist. Some of the bags have protective powers meanwhile others are powerful charms which are aimed at bringing good luck to its user. One of the most important conditions of such bags usually produced with animal skin is that, it is forbidden for water to touch them. If water touches them, they either loss their powers or have an adverse effect on the user.

\section{Social Functions of Bags}

Bags have a great social role, some are used as gifts, and others are used to store as well as carry other objects such as the cup. Many Bamenda Grassfields people usually carry the bags and the cups to different ceremonies. Greetings from Cameroon, you are welcome etc, are some of the inscriptions that we can find on bags which are given out as gifts. Sometimes such bags will carry the colours of the flag (green, red and yellow) as portrayed in the plate below. 


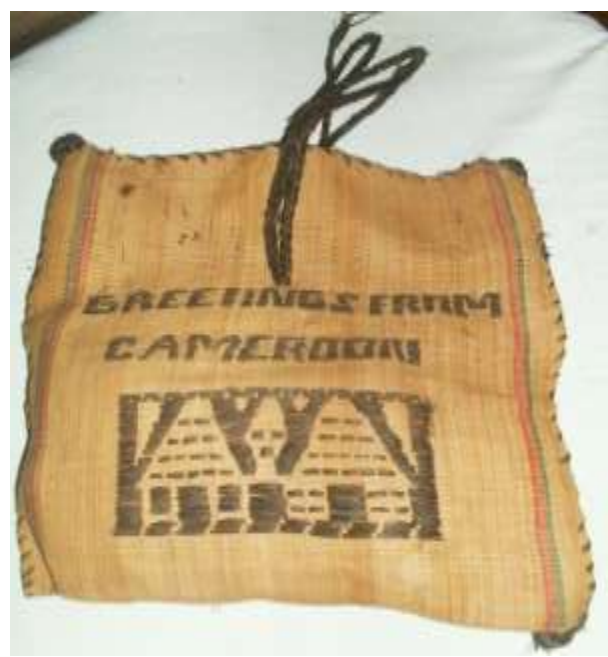

Plate 23: A bag meant to be offered as a gift. Photo Tikere (10/09/2015)

Gifts play a very important role in the lives of Bamenda Grassfields people in particular in Africans in general. These objects often portray the relationship that exists between individuals and nationals. When visited, the host usually offers a symbolic gifts which as acts as a souvenir to his or her visitor. This is a bond that ties the two persons or societies together.

During the annual dance in most Bamenda Grassfields chiefdoms, women and men alike dance the colourful fon's dance with the traditional bags hanging on their hands for the women and on the shoulder for the men. The bag here adds more beauty and honour to the owner's personality. They can identify themselves with their traditional and culture.

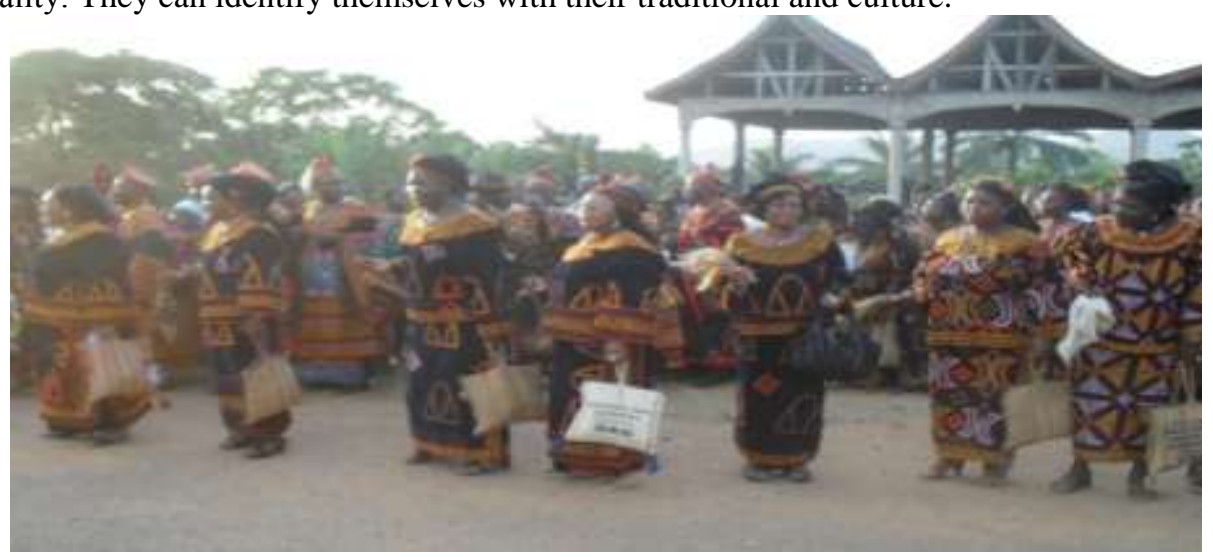

Plate 24: Women dancing in the fon's dance. Photo Tikere (17/12/2012)

At some point of the celebration, the participants sit and are entertained with food and palm wine provided by the palace. The palace does not provide the cups with which this drink has to be served because it is the culture of the people that a real 'man' of the Bamenda Grassfields culture always goes to a ceremony with his bags in which is usually found the cup, cola nut and other cultural elements.

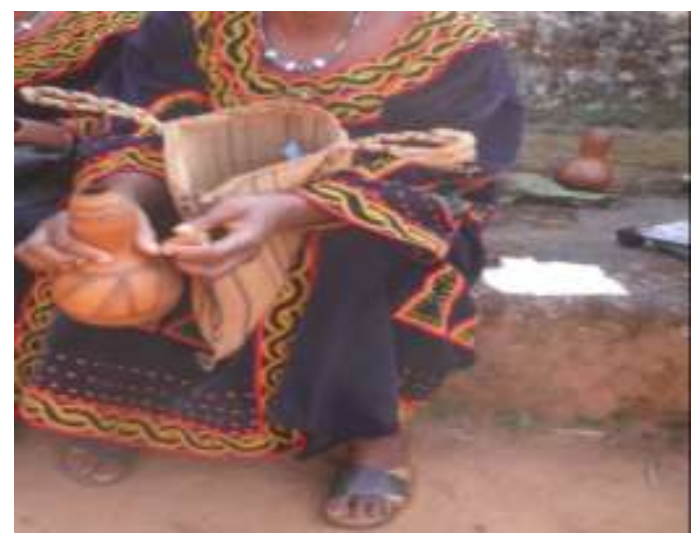

Plate 25: A woman at a cultural ceremony. Photo Tikere (17/12/2012)

Some people especially the men will often carry their traditional medicine which is either meant to guide or protect them in case of danger in their bags. And when they carry their bags and meet a woman in a stream doing some laundry, a kind man will ask her to come out before he crosses the bridge, this in order that the medicine in his bag should not affect the woman. Due to the fact that it 
is already the way of life of these people, when a woman who is doing laundry sees a man either young or old coming, she first of all observes very well, if he is carrying a bag, she will hastily leave the stream for him to cross first before she returns to the stream and continue with her work.

If a man, especially an elderly man meets a number of people conversing, if he is carrying a bag, they will move in one direction to allow the old man to pass. It is believed that if the old man passes in their midst, they are going to be affected by the contain of his bag.

\section{Economical functions of bags}

The functions of traditional bags may be obtained through use. For those involve in their production, they are in the first place commodities; products which can be traded, bought or sold mainly to acquire income. But before pre-colonial times, these bags were not manufactured for economic purpose - they were mainly to serve the chiefdom in varied domains, with most of them having political and magico-religious functions. This explains why many of the palaces in the Grassfields of Cameroon had to hold their producers in high esteem because they produce objects in the tribal style, articles which conformed to the tribal tradition of designs, motifs and symbols. Furthermore, in the pre-colonial era, the fons, nobles and secret societies served as the major market for these objects for they were made mainly for them. With colonisation, traditional bags were highly priced by tourists and art collectors and this made these cultural artifacts to become highly in demand that many weavers and chiefdoms started using them as commodities.

The economic importance of trade in traditional bags is therefore a very recent development per say, and this could largely be due to the fact that Grassfields woven objects including those of Bamenda Grassfields are famous for their aesthetic qualities. Bags were easily adaptable for men of different socio-political ranks and prestige. Bamenda Grassfields bags were and are still highly commanded and sought after throughout the region, both for their superb craftsmanship as well as their special metaphysical power they were believed to possess.

More so, elaborately woven bags made for both daily and ceremonial use, were and are objects of frequent exchange among the various chiefdoms of the Grassfields. The commercialisation of these items is done by both the male and female folk although its production is restricted only to the male. The female do not take part in its manufacture because of the taboo that surrounds the production.

The marketing of bags is done at the local as well as external level. The weekly markets are not the only outlet for local weavers, who are usually capable to commercialise their objects directly from their compounds, to art shops, handicraft centres, museum owners and to tourists. Although most weavers are not full time workers, majority of them, notwithstanding their ages, are able to contribute substantially to the household income - medical expenses of family and relations (children, wives, grandparents, grandchildren, aunts, uncles among others), schools fees and pay for the apprenticeship of their children and other relations who are not engaged in weaving.

The costs of traditional bags vary from one producer to another. The cost of a bag is determined by the material used in its production and its quality. A bag made of animal skin can costs forty thousand (40.000) francs meanwhile a fibre bag costs thirty thousand (30.000) francs. The costs of a bag intended for a gift depends mainly on the inscriptions that appear on it. To many weavers therefore, a good bag demands much time and good quality material. Some of the weavers note that the prices of traditional bag have dropped. Despite this drop in the prices, there are still a handful of master weavers maintain the tribal style and tradition in the production of good and quality objects. Such artists put the blames on young untalented artisans who have flooded the market with 'just any kind' of products, articles of low quality, because they are struggling for survival.

Museum owners are equally potential consumers of bags. They come from all over the country, buy things that have already been produced and place commands on others. Tourists, missionaries and important personalities in the North West Region also purchase bags. Art collectors, art lovers and tourists pay less on an object than the authors wanted. This has pushed most weavers to hack their products in the streets of major towns in Cameroon.

\section{Symbols represented on traditional bags and their Significance}

The motifs represented on the Bamenda Grassfields traditional bags are anthropomorphic, zoomorphic as well as geometric. Some of the symbols usually found on bags are the leopard, cowry shells, the lizard, the ndop. Geometric figure designed on bags are the circle, the triangle to mention these few.

\begin{tabular}{|l|c|c|c|c|c|c|}
\hline Motif & Bafut & Kedjom & Oku & Kom & Bambui \\
\hline \multirow{2}{*}{ Animal } & Leopard & Nkanse & Manh & Bah & Nyam abo & Kalong \\
\cline { 2 - 7 } & Lizard & Nkongse & Kebas & Nkesakenyam & Abas & Afuh \\
\hline Inanimate & Cowry & Agheh & Kueh & Wekelel & Igwo & Agheh \\
\hline $\begin{array}{l}\text { Geometric } \\
\text { figures }\end{array}$ & Cycle & $\begin{array}{c}\text { Nkangse } \\
\text { ikarese }\end{array}$ & Nkale & Eykal & Nkal & Nkankka'a \\
\hline
\end{tabular}


Such motifs have cultural meanings that can be read or interpreted only by those who are rooted in the culture of this region. Each emblematic symbol is associated with a specific personality.

\section{The Leopard}

The leopard (Pantherapardus), is a member of the Felidae family and the smallest of the four "big cats" in the genus Panthera, the other three being the tiger, lion and jaguar. Leopards live mainly in grasslands, woodlands and riverside forests. While they are usually associated with the savanna and rainforest, leopards are exceptionally adaptable. The leopard is solitary and, aside from mating, interactions between individuals appear to be infrequent.

Leopards are generally considered to be nocturnal, agile and stealthy predators. Although smaller than the other members of the Panthera genus, the leopard is still able to take large prey given its massive skull that well utilizes powerful jaw muscles. Antelopes and deers provide a majority of the leopard's prey.

The leopard is known for its ability in climbing, and it has been observed resting on tree branches during the day, dragging its kills up trees and hanging them there. They are capable of carrying animals up to three times their own weight this way. The leopard is the only big cat known to carry its prey up into a tree. It is a powerful swimmer, although not as strong as some other big cats, such as the tiger. Leopards are versatile, opportunistic hunters. In the open savannah, they are most successful when hunting between sunset and sunrise, though they may hunt during the day.

Leopards have been known to humans since pre-history and have featured in the art, mythology and folklore of many countries where they have historically occurred, such as ancient Greece, Persia and Rome, as well as somewhere they have not existed for several millennia, such as England. The modern use of the leopard as an emblem for sport or a coat of arms is much more restricted to Africa, and through numerous products (http://en.wikipedia.og/wiki/Leopard).

According to Notué and Triaca (2000: 68) the leopard is a large elegant and powerful feline, with elongated forms. Thanks to its cunning attitude, power and ferocity, it is one of the most feared animals and, as such, one of the most respected in the African jungle. Knopfli (1999: 34) defines the leopard as a large feline, powerful, fast-running and flesh-eating animal, active particularly at night and very unpredictable. Its preys are mainly big field animals such as antelopes, cows and goats.

Mankon beliefs give this creature many powers. It is the perfect symbol of royalty and is associated with political and judicial authority as well as symbolising strength, the power of the fon, prestige and the greatness of royalty. Besides, the fon is indeed called "leopard" and his children "those" of this animal (Notué and Triaca, 2000: 68).

Bamenda Grassfields people give a lot of respect and honour to the manh- the leopard and this could be seen in the fact that a hunter who kills this animal is awarded a traditional title - a red feather as a mark of bravery and courage. In those days, such a hunter was to be given a raffia bush and one of the fon's daughters as a wife, for he had the power and wit to overcome such an animal which itself had power over some animals in the forest. Strength and wit therefore were two criteria that the fon used to select husbands for his daughters. A powerful man will always protect and fend for his family. In addition, getting married to a princess in the Bamenda Grassfields was an honour and this encouraged many young men to work hard to have the privilege to marry the daughter of the palace.

To demonstrate its importance in the Bamenda Grassfields, it is represented as a motif on bags. Such an emblematic object is reserved for the highest ranking personality of the chiefdom - the fon.

Just as the fon uses the skin of the tiger, he uses that of the leopard to rest his feet on its coat, to absorb the leopard's power. It is believed that when this is done, the fon can transform into a leopard when need arises. When there is a problem in the palace to escape, he changes into a leopard. He can equally do so when he wants to go to somewhere either in or out of the chiefdom without anyone's knowledge. The leopard therefore is a symbol of honour, protection and courage.

\section{The Cowry}

Cowryis the common name for a group of small to large marine gastropods in the family Cypraeidae. The word cowry is also often used to refer to the shells of these snails. Many people find the very rounded, shiny, porcelain-like shells of cowries pleasing to look at and to handle. Shells of certain species have historically being used, in the past and present, very extensively in jewellery, and for other decorative and ceremonial purposes.

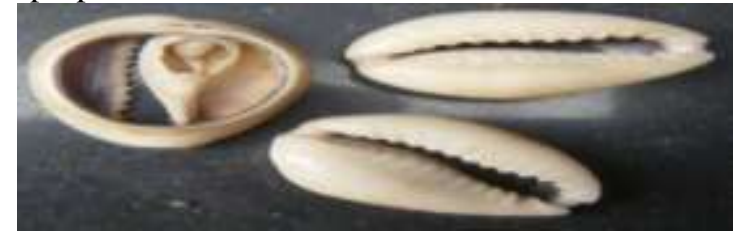

Plate 26: /Kueh/ Cowries. Photo: Tikere (10/01/11) 
The shells of cowries are almost always smooth and shiny and more or less egg-shaped, with a long, narrow, slit-like opening (aperture). The shells of cowries were used for centuries as a currency in Africa. Huge amounts of cowries were introduced into Africa by western nations during the period of slave trade. The Ghanaian unit of currency known as the Ghanaian cedi was named after cowry shells. Starting over three thousand years ago, cowry shells, or copies of the shells, were used as Chinese currency. They were also used as means of exchange in India. (http://en.wikipedia.og/wiki/cowry)

On the Bamenda Plateau, as Nkwi and Warnier (1982:92) note that cowries were known as aghié, whereas elsewhere, they were called mbefu, which means "white money" or "white grains". According to Nkwi and Warnier (1982:92) and Knopfli (1999: 65) cowry shells are valuable because in pre-colonial times they were used as money in many parts of Cameroon. Knopfli (1999: 65) continues by saying that anything could be bought with cowries, even women, for they were one of the goods to be bought with money.

Cowry shells were replaced by copper rods and the former's function changed in most Grassfields chiefdoms. Cowries were used as an ornament and a status symbol by the fons and chiefs. Chiefly wives wore and still wear strings of them as necklaces, armlets or anklets. Fon's wives are marked out by wearing cowry shells as they are traditionally respected in these chiefdoms for being of greater social position than other women.

The cowry is also used as decorative and identification marks on art objects like bags, bowls, walking sticks, embroidered costumes, stools, houseposts, doorframes as well as title drinking vessels. These objects are set aside for the fon, members of the royal family and notables. The sign symbolises dignity and thus it is an insignia of dignitaries.

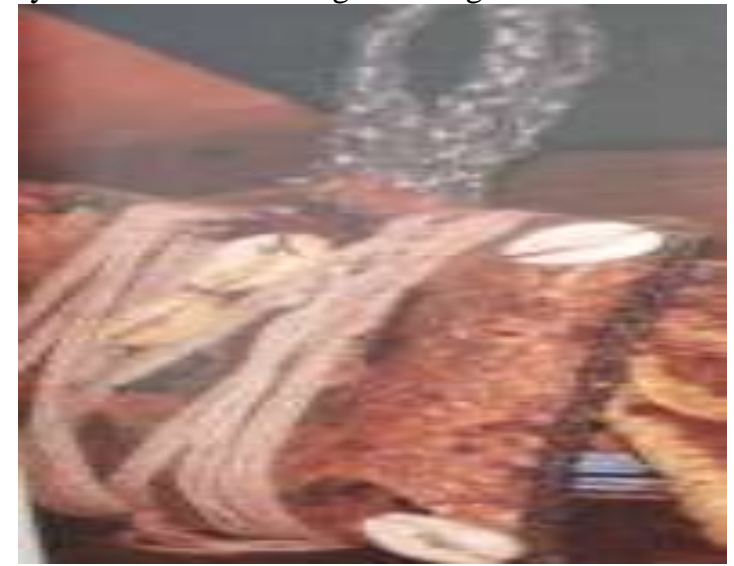

Plate 27: The bag of a traditional healer. Photo: Tikere (16/10/2017)

Cowry shells are equally used by diviners for divination. A diviner will use them together with other objects, and throws them on the ground. By shaking and throwing them on the ground, he looks at the symbol which comes on top. From this symbol, he could discern what hopes and fears are in the minds of the patient or person he is carrying out his divination. He becomes a sort of psychoanalyst at an encounter group of the whole chiefdom. These cowries can be used for individual consultation but their main function is to inform the diviner what is in the mind of an individual by encouraging that individual to reveal himself or herself to the diviner. This object gives the diviner channels of communication with the society's gods and they help him to preserve the features of a particular individual soul.

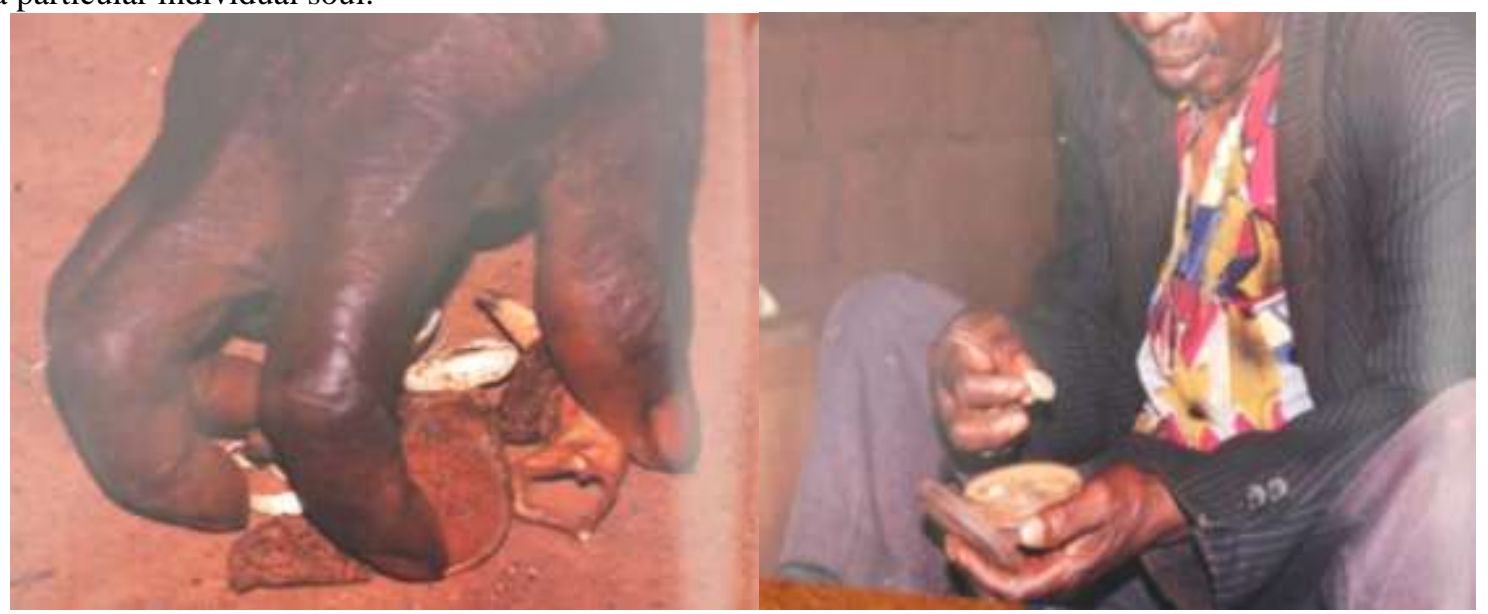

Plates 28 and 29: A diviner communicating with the gods. Photo: Tikere (16/10/2017)

\section{The Lizard}

Lizards are small to average sized reptiles belonging to the family Gekkonidae, found in warm climates throughout the world. All lizards have no eyelids and instead have a transparent membrane which they lick to clean. Many species will, in defence, expel a 
foul-smelling material and faeces onto their aggressors. There are also many species that will drop their tails in defence, a process called autotomy.

Many species are well known for their specialized toe pads that enable them to climb smooth and vertical surfaces, and even cross indoor ceilings with ease. The toes of the creature have a special adaptation that allows them to adhere to most surfaces without the use of liquids or surface tension. They feed on insects, including mosquitoes http://en.wikipedia.og/wiki/Lizard.

Different kinds of lizards are common in Bamenda Grassfields, ranging from the small insectivorous and peaceful gecko or house lizard, to the giant lizard living in the bush. The people describe various characteristics of lizards. All types of lizards have long bodies and long tails, and their skin is covered with scales almost like fish. A lizard can lost its tail without being cut and grow a new one. The lizard is the fastest climber not only on trees but even on smooth surfaces, as if it had sticky fingers and toes.

The rainbow lizard is used by witch doctors to send and direct lightning. For instance, in cases of theft, adultery, land stealing and the like, the offended person consults angambeman - a diviner asking him to kill the wrongdoer by causing lightning to strike his compound. The ngambeman will catch this lizard, put medicine into its mouth and gunpowder on its back. He then asks the plaintiff to strike a match and burn the gunpowder on the lizard. The gunpowder puffs and the lizard runs away to the wrongdoer's compound and hides there. Before long lightning will strike that compound and burn it down, possibly at the same time striking and killing the man (Knopfli, 1999: 57).

The lizard as a symbol is represented on stools, bags, thrones, houseposts, doorframes and walking sticks. Bamenda Grassfields people believe that this lizard is the rainbow lizard. This animal which has a reddish-dark skin is very poisonous and dreadful. It is known in Kedjom as kebas. If it bites someone, it is believed it cannot be cured, thus the people always watch out for it and would not let it escape if seen. Items that carry the lizard symbol are used by the fons, chiefs and king makers. Due to their poisonous nature, it is believed that the notables who constitute part of the ruling body having acquired the poisonous characteristics of the lizard, will use it to guard against enemies from within and out of Bamenda Grassfields. The lizard in this case stands for protection.

Although the lizard is poisonous, if killed, the head is cut and combined with other products to produce traditional medicine fefehkeloh in Kedjom commonly called "black medicine" in Pidgin English. Black medicine can be used to cure stomach-ache or disorder, and snake bites. This medicine is produced by a category of people in Kedjom known as ngang. They are sub chiefs and king makers. Because of its ability to serve as medicine that heals sick people makes it an omen- and a symbol of abundant life.

\section{The Ndop Fabric}

This is one of the most important insignias of royalty in the Bamenda Grassfields of Cameroon. If seen in use anywhere in the entire chiefdom, it represents the power and might of the fon. This fabric is used to produce a variety of art objects ranging from clothes to bags. Objects which are made with this fabric are used in ceremonies like the fon's dance, enthronement of a fon, and succession of a big notable. During such occasion, the area where the fon sits is decorated with the ndop fabric to demonstrate his majesty. This material is usually blue and white in colour having some geometric motifs like the circle and triangles.

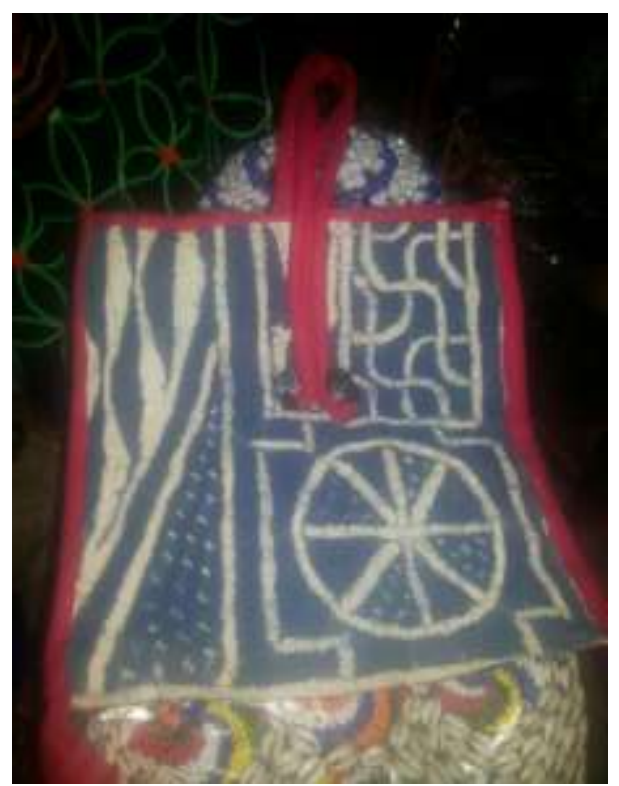

Plate 30: A traditional bag made with the ndop fabric. Photo: Tikere (10/01/11) 


\section{The Circle}

The circle is the most emblematic of all geometric designs used on Bamenda Grassfields arts in general and on bags in particular. This motif is represented on varied art forms. In sculpture, it is found on stools and bangles and on embroidered costumes. ${ }^{2}$ Such an object on which a circle is adorned is used exclusively by the fon. A bag with circle emblem usually carries a single circle as could be seen in the plate above. The circle makes the item very beautiful just by looking at it. But the circle go beyond mere decoration. It is regarded as the symbol of the moon. Their prominence in the sky and their regular cycle of phases have since ancient times made the moon an important cultural influence on language, calendars, art and mythology (http://.wikipedia.org/wiki/Moon).

The fon is the symbol of the moon and like one, he is expected to protect everyone even criminals who find their way to the palace. As an embodiment of peace, the fon or ntoh is there to ensure peace in the entire chiefdom. The fon is the father of all and unifies the village around himself. He is therefore not supposed to be engaged in repression and as already discussed, repression and social control must deal with polluting actions, and the fon must belong to the opposite pole of human society, the cultural pole, which is free from pollution and danger. He could only take part in social control and repression as a moderator.

Some people believe that this motif stands for the moon because of its circular nature. ${ }^{3}$ The moon is Earth's only natural satellite and the fifth largest satellite in the solar system. It is the brightest object in the sky after the sun. The motif portrayed here is that of a full moon, the moon which comes out at night. The night is regarded as a dangerous period of the day when many funny things happen. The moon therefore provides light to all irrespective of the sex, age or social status. Everyone even the dangerous of all thieves also benefits from this gift of nature. The fon who uses art object with such a symbol (the symbol) is regarded as a model, he is expected to set an example for others to follow and this explains why he is looked upon to provide the symbolic light that shines indiscriminately to every village folk. The fon must not look and treat certain villagers as superior to others, he has a duty to protect, love, welcome everyone in the same manner like the moon. The moon therefore stands for peace, clarity, purity and unity.

There is yet another interpretation of the circle. It is considered to signify the sun. The sun is the star at the centre of the solar system. It is the star that the earth spins around. It is almost perfectly spherical and provides heat and sunlight, it is the Earth's primary source of energy. Solar energy can be harnessed by a variety of natural and synthetic process - photosynthesis by plants captures the energy of sunlight and converts it to chemical form oxygen, and reduced conversion by solar cells are used by solar power equipment to generate electricity or to do other useful work, sometimes employing concentrating solar power. In many prehistoric and ancient cultures, the sun was thought to be a solar deity or other supernatural phenomenon. Worship of the sun was central to civilisations such as the Inca of South America and the Aztecs of what is now Mexico. Many ancient monuments were constructed with solar phenomena in mind (http://en.wikipedia.org/wiki/sun).

The fon in most Bamenda Grassfields chiefdoms is referred to as the sun and this may be because like the sun which is at the centre of the solar system that the Earth revolves around, he is at the centre of a very singular cultural manifestation in the chiefdom. Like the sun, the fon unites his people around him, people to whom he has to from time to time provide palm oil and salt. This demonstrates a strong sense of social organisation of these chiefdoms that have brought up grandiose arts among which is the traditional bag. As a functional sign, the sun in these societies is regarded as a liturgical motif represented on such objects as bags, stools and embroidered costumes which are used by the fon for specific rites or during any other celebration which signifies the way of life of the people. The fon here is the symbol of unity.

The fon is considered as a special light of the sun that shines in the lives of the people, light which shines for all irrespective of age and size. This symbolism of the sun associating it with the fon may be due to the fact that it provides light which does not only serve humans, but is also very invaluable for plants that use it to manufacture food through a process known as photosynthesis. The value of plants in the life of a people cannot be over emphasised. It serves as food, as medicine, as home of spirits, as one of the main raw materials of the bag.

\section{The Dynamics of Traditional Bags}

Considering the fact that there is no aspect of culture which is static, the traditional bags of the Bamenda Grassfields have witnessed some changes in recent years especially in the domain of production and use. As mentioned above, traditional Bamenda Grassfields bags were manufactured out of three major raw materials: animal skin, fibre and the ndop fabric. Today, bags especially those reserved for commoners are produced from nylon. Such bags are believed to be resistant because of the material which has been used in its production. To the local people therefore nylon bags can last for many years and they can be easily washed when dirty. Below is an example of a nylon bag made in Mankon Bamenda.

\footnotetext{
${ }^{2}$ The embroidered robe the fon uses bears only a single moon on the back part of the dress. This moon is believed to provide a symbolic light to the people who are all under the fon's leadership.

${ }^{3}$ The moon is the object, similar to a planet, which moves in the sky around the Earth once every 28 days and which can often be seen clearly at night when it shines with the light coming from the sun.
} 


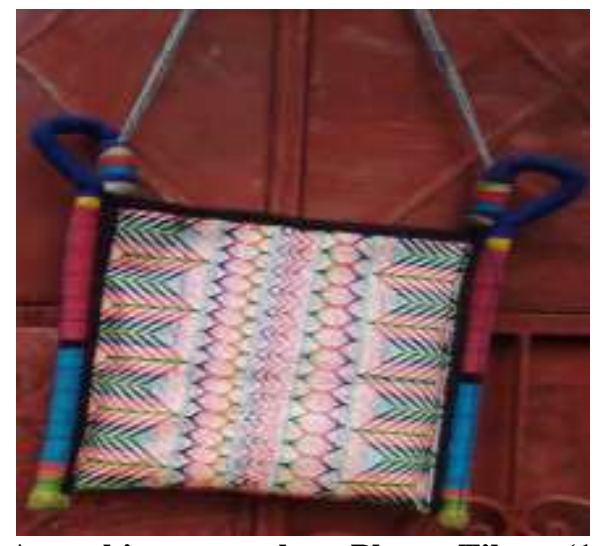

Plate 31: A machine woven bag. Photo: Tikere (10/01/2019)

Nylon bags are woven using machines and not the hand as it is commonly done with the traditional bags. These bags like most modern art objects do not really fulfil the functions the traditional bags would because they are too colourful and do not reflect the tradition of it producers. The producer of this bag does not take into consideration the tribal style, the object does not conformed to the tribal tradition of designs, motifs and symbols.

Today, bags are carried just on any side of the body on like before when bags were carried only on the left side. In the days of old, bags be they those hung on the hand or on the shoulder, this was supposed to be on the left side of the body. The left side of the body is looked upon as the weaker side of the body equated to the 'woman side of the body' so the power of the bag therefore reinforces this part of the body.

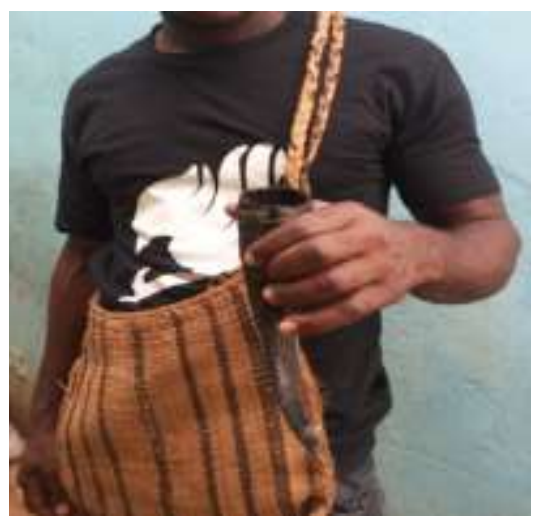

Plate 32: A young man carrying a traditional bag. Photo: Tikere (10/01/2019)

The plate above portrays a young man who hangs his bag on the right side of the body. This only helps to remind us that as time changes, the daily life of the people too change and as Knopfli (1999: 8) states that nowadays young people are brought up in an environment made of plastic and concrete. They drink from glasses, eat from enamel plates; store their belongings in suitcases or cartons. They do not manufacture what they use on a daily bases.

Most weavers in the field remarked that the palace or the fon and his notables were the major consumers of traditional bags. At first this category provided a major market for crafts since most of the products were for them. But today, because the palaces generally do not buy crafts well, some craftsmen do not see the need to produce such crafts used by traditional leaders. They say that even when the palace gives a command for a bag to be produced, the palace does not pay an amount that is encouraging, an amount that a museum owner or a tourist could have paid. Meaning that what the palace offers is only compensation which is a sign of encouragement. At times they can give to the palace free of charge because they will first of all have a name at the village level and the product can also help to sell or expose them in and out of society.

\section{Conclusion}

The traditional bag of the Bamenda Grassfieldsis a very important part of the people's cultural heritage. These bags are produced by the male folk who use a variety of natural resources got from the immediate environment. This art object played a fundamental role in the lives of the individuals in particular and the culture in general. This explains why many of the palaces had to hold their producers in very high esteem because they produce objects in the tribal style, articles which conformed to the tribal tradition of designs, motifs and symbols. But the traditional bag of the Bamenda Grassfields has witnessed some changes ever since this part of the country came into contact with the external world. 


\section{References}

- Boas, Franz,

1927. Primitive Art Oslo

- Knopfli, Hans,

1997. Crafts and Technologies: Some Traditional Craftsmen of the Western Grassland of Cameroon. (British Museum Occasional Paper $\mathrm{N}^{0}$. 107). Lonaon: Trustees of the British Museum.

1999. Sculpture and Symbolism. Crafts and Techniques: Some Traditional Craftsmen of the Western Grassfield Woodcarvers and blacksmiths (part 2). Basel: Basel Mission.

2001. Crafts and Technologies: Some Traditional Craftsmen and Women in the Western Grasslands of Cameroon(Part 3). Basel: Basel Mission.

- Moffor, Exodus Tikere,

2005. Culture Portrayed in Handicrafts. A Case Study of Bambui Society in the Grassfield of Cameroon. Masters Dissertation, Department of Sociology and Anthropology: The University of Yaounde 1.

2008. Symbolism on Handicrafts in the Bambui Fondom (Western Grassfield - Cameroon).

Higher Diploma Dissertation, Department of Anthropology: The University of Yaounde 1.

- Nkwi, Paul,

1987, Traditional Diplomacy: A Study of Inter-Chiefdom Relations in the Western Grassfieds, North West Province of Cameroon. Yaoundé.

- Nkwi and Warnier,

1982, Elements for the History of the Western Grassfields. Yaoundé: Department of Sociology University of Yaoundé.

- Notué, Jean-Pual and Triaca Bianca,

2000. The Treasure of the Mankon Kindom: Cultural Objects of the Royal Palace. Yaoundé

- Northern, Tamara,

1975, The Signs of the Leopard Beaded Art of Cameroon. New York. The William Benton Museum of Art.

- Warnier, Jean-Pierre,

1975. Pre-colonial Mankon: The Development of a Cameroon Chiefdom in its Regional Setting. Ph.D Thesis; Philadelphia: University of Pennsylvania.

1985. Echanges, développement et hiérarchies dans le Bamenda Précolonial. Wiesbaden and Stuttgart, Steiner Verlag.

- Venice and Alastair Lamb,

1981. Au Cameroon, Weaving - Tissage. Hertingfordbany, Hertfordshire, Roxford Books

- http://en.wikipedia.og/wiki/cowry

- http://en.wikipedia.og/wiki/Lizard

- http://.wikipedia.org/wiki/Moon

- http://en.wikipedia.org/wiki/sun 